\title{
Predicting the Floc Characteristics and Settling Velocity of Flocs under Variable Dosage of Polyacrylamide
}

\author{
Zhi-peng Shi ${ }^{1, \mathrm{a}}$, Gen-guang Zhang ${ }^{1, \mathrm{~b}, *}$, Guo-liang Pei ${ }^{2}$, and Guo-yun Zhang ${ }^{2}$ \\ 1 College of Water Resources and Architectural Engineering, Northwest A\&F University, Yangling, 712100, \\ P. R. China \\ 2 State Key Laboratory of Crop Stress Biology for Arid Areas, Northwest A\&F University, Yangling, \\ 712100, P. R. China \\ E-mail: aszp821002@126.com(Corresponding author), bzgg64@163.com
}

\begin{abstract}
In this study, floc characteristics such as fractal dimension and settling velocity were investigated through a flocculantion process with a polyacrylamide (PAM) flocculant over a range of suspended particle concentrations, suspension type and flocculant dosage. The floc's structure and morphology were characterized by optical microscopy and scanning electron microscopy (SEM) methods. Floc settling velocity was measured in a settling column in a laboratory. The results showed that, the surface fractal dimension ranged from 1.044 to 1.415 , which quantitatively confirmed the round and layered structure of flocs observed in SEM analyses. The PAM flocculant was proved to be more effective in flocculantion process, increasing the settling velocity. Therefore, an appropriate PAM dosage is an excellent candidate as efficient flocculant. A possible flocculantion mechanism for PAM was further analyzed. For alkaline or neutral environments, adsorption and bridging effects are dominant while charge neutralization is favored in acidic conditions.
\end{abstract}

Keywords: Flocculation characteristic, polyacrylamide, fractal dimension, settling velocity, flocculation mechanism.

ENGINEERING JOURNAL Volume 21 Issue 3

Received 27 July 2016

Accepted 14 December 2016

Published 15 June 2017

Online at http://www.engj.org/

DOI:10.4186/ej.2017.21.3.113 


\section{Introduction}

Sewage discharged by paper mill, coal mine and polluted rivers generally contains suspended particles and toxic substances. Accordingly, sewage must be treated to remove the particles and harmful substances before discharging. Flocculation is an essential process for conventional water treatment. $\mathrm{Al}(\mathrm{III})$ and polyaluminum chloride, as coagulants, have been used and investigated in many previous studies for many years $[1,2,3]$. It is necessary to find a flocculant that is more economical, easier to operate and less contamination. In recent years, the application of dissolvable flocculant with high molecular weight has been received close attentions in the process of wastewater treatment. Polyacrylamide (PAM), an organic flocculant, contains sulfonic acid, phosphoric acid, or carboxylic acid functional groups [4, 5]. It plays a key role in solid-liquid separation by aggregation of suspended particles [6].

Flocs that are formed by various flocculant can show different floc characteristics and these will affect the dosage of the flocculant and settling velocities of suspended particles. They are two key parameters in the process of flocculation. For non-cohesive particles, settling velocity is a function of particle size, particle shape and specific gravity. For flocs, settling velocity, floc size and excess density all become dynamic constituents. Fractal dimension, one of floc characteristics, is adopted to calculate the settling velocities of flocs (Eq. (1)).

$$
v_{s t}=\frac{1}{18} \theta g \frac{\rho_{p}-\rho_{w}}{\mu} d_{50}^{3-D_{f}} \frac{d^{D_{f}-1}}{1+0.15 \operatorname{Re}^{0.687}} \phi
$$

where $v_{s t}$ is the settling velocity of an individual floc, $\theta$ is a particle shape factor, $g$ is the gravitation acceleration, $\mu$ is the water dynamic viscosity, $\rho_{p}$ and $\rho_{w}$ are the density of primary particles and the water density respectively, $d_{50}$ is the median size, $d$ is the floc size, $D_{f}$ is the fractal dimension, $\phi$ is the effect of the size distribution of the primary particles, Re is the particle Reynolds number [7]. The fractional dimension and various model coefficients are considered in the Eq. (1). Also, Eq. (2) [8, 9] assumes that the fractal dimension of the aggregate is equal to that of primary particles.

$$
N \sim\left(\frac{d}{d_{p}}\right)^{D_{f}}
$$

where $d_{p}$ is the size of the primary particles. An empirically settling velocity expression is given by Soulsby (1997) [10]:

$$
v_{s t}=\frac{v}{d}\left(\left[10.36^{2}+1.049 D_{*}^{3}\right]^{1 / 2}-10.36\right)
$$

where $D_{*}=\left[g\left(\rho_{p} / \rho_{w}-1\right) / v^{2}\right]^{1 / 3} d, v$ is the kinematic viscosity.

Several formulas have been proposed for settling velocity, unfortunately, due to the non-linearity of the flocculation process, floc is difficult to control and settling velocity fail to predict adequately. Even more importantly, current methods of settling velocity do not take into consideration the kind and dosage of flocculant. A better understanding of the floc characteristics under various conditions would allow for both more accurate flocculation process and an improved understanding of the flocculation mechanism.

In this work, flocculation of sand, fly ash and coal suspensions with PAM flocculant have been carried out with different dosing conditions and with different suspensions. The main aims of the work were: To compare the effects of PAM flocculant on the structure of flocs by optical microscopy and SEM; to investigate the fractal dimension of flocs; to predict the optimal dosage of PAM based on settling velocity and to gain further insight into the mechanism of floc formation.

\section{Materials and Methods}

\subsection{Materials}

Due to differing shape, size, specific gravity and density of sand, fly ash and coal they exhibit vastly different settling velocities and flocculation characteristics. Therefore, they were used as suspended 
sediments in the experiments. A laser particle analyser (Winner2008D, Jinan Winner particle Instrument Co., Ltd., China) was used prior to the experiment to measure the deflocculated grain size distribution of the sample (Fig. 1). Deflocculation was obtained by sonicating the sample for $10 \mathrm{~min}$ prior to measurement in the laser particle analyser. The $d_{50}$ of sand, fly ash and coal was $39.63 \mu \mathrm{m}, 13.73 \mu \mathrm{m}$ and $77.25 \mu \mathrm{m}$ respectively. The specific density of sand, fly ash and coal was $2.65,2.3$ and 0.85 respectively. They were dispersed in $1000 \mathrm{~mL}$ of deionized water in a high-speed blender. Polyacrylamide (PAM, analytical grade; Tianjin Kermel Chemical Reagent Co., Ltd., China) was used as flocculant. Na-hexametaphosphate $\left(\left(\mathrm{NaP}_{3}\right)_{6}\right.$, Tianjin Bodi Chemical Co., Ltd., China) was selected as a chemical dispersant. The chemicals used in the experiments were of analytical grade and deionized (DI) water was employed for all experimental work. The main experiment equipment were: Electronic balance (SQP, Sartorius Scientific Instrument Co., Germany), Freeze drying machine (FD-1D-80, LaboGene companies, Denmark), Research grade microscope imaging system (U-HGLGPS, OLYMPUS company, Japan), Scanning electron microscope (S-4800, JEOL company, Japan).

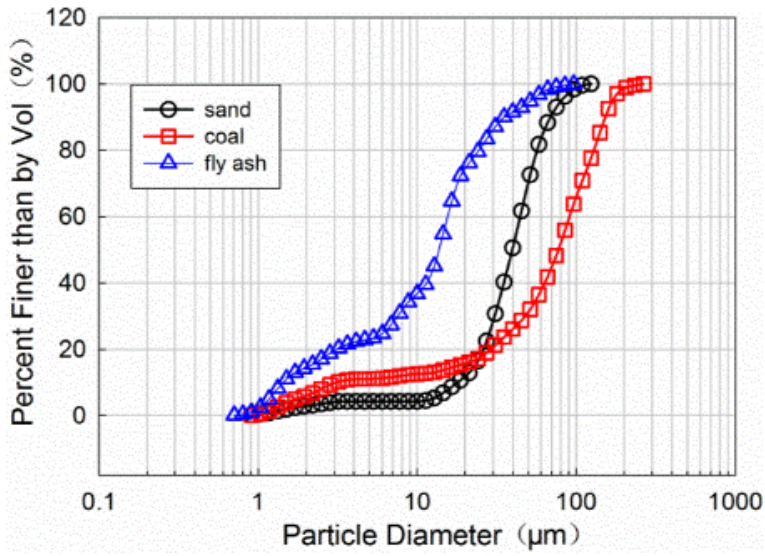

Fig. 1. Grain size distribution of the primary sediment sample used in the experiment

\subsection{Experimental Setup}

The experimental setup in this study uses a $1000 \mathrm{ml}$ measuring cylinder, a high-resolution optical microscope and a freeze drying machine (Fig. 2). The $1000 \mathrm{ml}$ measuring cylinder was used for flocculation reaction and measuring settling velocity. Flocs were extracted from the bottom of the cylinder by pipet. Then they were freeze dried and observed by an optical microscope and SEM. Details of the testing methods are provided below.

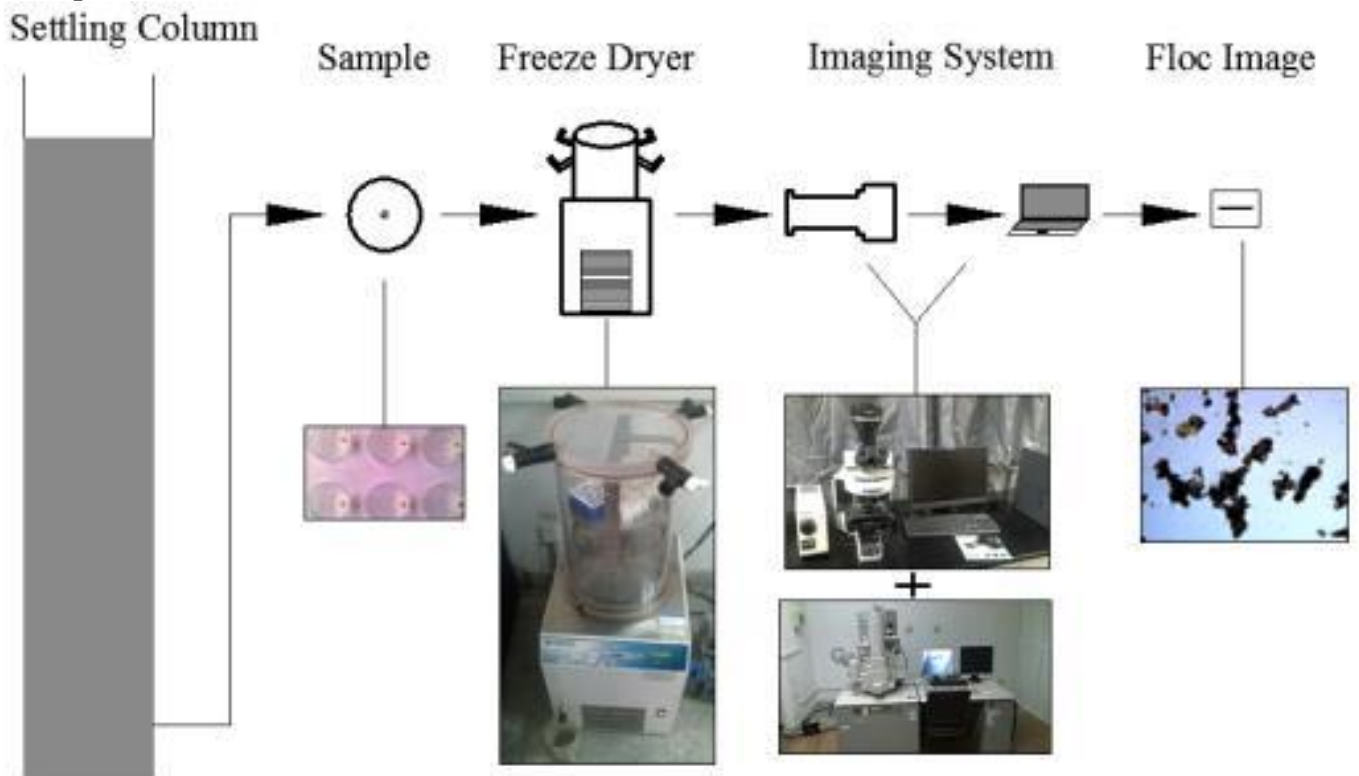

Fig. 2. Schematic of the setup for experiments with an example image 


\subsection{Flocculation Experiments}

Flocculation experiments were carried out using a program-controlled measuring cylinder apparatus at ambient temperature. An orthogonal experiment is conducted to find the optimal dosage for the PAM. According to the experimental design, the following experiments were performed (Table 1). "A" and "B" stand for concentration of suspension and concentration of PAM respectively. Three different suspensions were assessed: sand, fly ash and coal. In addition, the influence of PAM on the flocculation process was studied for each suspension.

Table 1. The factorial experiments of concentration of suspension and PAM.

\begin{tabular}{ccccccccc}
\hline Sample no. & A $(\mathrm{g} / \mathrm{L})$ & $\mathrm{B}(\mathrm{g} / \mathrm{L})$ & Sample no. & $\mathrm{A}(\mathrm{g} / \mathrm{L})$ & $\mathrm{B}(\mathrm{g} / \mathrm{L})$ & Sample no. & $\mathrm{A}(\mathrm{g} / \mathrm{L})$ & $\mathrm{B}(\mathrm{g} / \mathrm{L})$ \\
\hline 1 & 5 & 0 & 12 & 15 & 0 & 23 & 1 & 0.04 \\
2 & 5 & 0.002 & 13 & 15 & 0.002 & 24 & 3 & 0.04 \\
3 & 5 & 0.005 & 14 & 15 & 0.005 & 25 & 5 & 0.04 \\
4 & 5 & 0.01 & 15 & 15 & 0.01 & 26 & 7 & 0.04 \\
5 & 5 & 0.02 & 16 & 15 & 0.02 & 27 & 9 & 0.04 \\
6 & 5 & 0.03 & 17 & 15 & 0.03 & 28 & 15 & 0.04 \\
7 & 5 & 0.04 & 18 & 15 & 0.04 & 29 & 20 & 0.04 \\
8 & 5 & 0.05 & 19 & 15 & 0.05 & 30 & 30 & 0.04 \\
9 & 5 & 0.06 & 20 & 15 & 0.06 & & & \\
10 & 5 & 0.08 & 21 & 15 & 0.08 & & & \\
11 & 5 & 0.1 & 22 & 15 & 0.1 & & & \\
\hline
\end{tabular}

In a preliminary study, according to Table 1 , sand, fly ash and coal were added into $1 \mathrm{~L}$ deionized water respectively to give a required concentration. After $3 \mathrm{~min}$ of vigorous stirring at $200 \mathrm{rpm}$, with the help of $\left(\mathrm{NaPO}_{3}\right)_{6}$, the suspension were prepared. The stock solution of PAM was prepared using deionized water before test. The specific process consisted of an initial period of rapid stirring after suspension was mixed with PAM, followed by $5 \mathrm{~min}$ of slow stirring and finally settling for about two hours. The effects of different types of suspension at different concentrations were examined by a similar test procedure. After that, the flocs were collected and analyzed for their characteristics.

The flocs were transferred from the measuring cylinder to glass slides using a pipet with an $8 \mathrm{~mm}$ inner diameter mouth [11-13]. One end of the pipet was inserted just below the surface of the water and the other end was controlled by fingers. The flocs were disposed of and redraw whenever the collecting process was not done carefully enough. Then the flocs on the glass slides were freeze-dried. Finally an image of the flocs was captured by a microscope imaging system. The images were analyzed by Image-pro Plus 6.0 software [14].

\subsection{Measurement of Settling Velocity}

After flocculation, sedimentation tests were followed in order to calculate the settling velocity. A $1000 \mathrm{ml}$ measuring cylinder used for measuring flocs settling velocity had an inner diameter of $50 \mathrm{~mm}$ and a height of $400 \mathrm{~mm}$, which was sufficient to avoid wall effects and to allow flocs to reach terminal velocity [13, 15]. Settling velocity was calculated using the distance traveled by a floc and the travel time measured by a digital-display stopwatch. If the fluid within the cylinder is assumed to be still, the settling velocity of each floc is determined as

$$
v_{s t}=\frac{\Delta Z}{\Delta t}
$$

where $\Delta Z$ is the vertical displacement of the floc centroid, $\Delta t$ is the time over which the floc was tracked. This approach has already been used successfully in previous studies and it has been demonstrated that the test method is feasible [16-18]. 


\subsection{Measurement of Fractal Dimensions}

"Self-similarity" [19], the similarity of observed structures regardless of the scale of magnification, is indicative of their fractal character. For self-similar fractal, the Hausdorff dimension (Eq. (5)) is adopted to calculate the fractal dimension.

$$
D_{f}=\lim _{r \rightarrow 0} \frac{\log \left(N_{r}\right)}{\log (1 / r)}
$$

where $D_{f}$ is the fractal dimension, $N_{r}$ is a number covering its image, $r$ is the size [20, 21].

\section{Results and Discussion}

\subsection{Morphological Analysis}

Flocs falling through the still water in the measuring cylinder were imaged by research grade microscope imaging system and scanning electron microscope (Fig. 3) [22-24]. The first three images correspond to flocs produced by sand, fly ash, coal and PAM respectively and they were examined by optical microscopy. The last one illustrate flocs produced by sand with PAM was examined by scanning electron microscope. Although the first three flocs were obtained with the use of different suspensions (sand, fly ash and coal), no significant differences were observed in their structure. The noted differences can be attributed to the cuboid shape of sand particles, the spherical shape of fly ash and the irregular shape of coal. These particles are the building blocks of clusters which gather and flocculate with PAM to produce flocs. Similar images of flocs were descripted by Kumar et al. (2010) [16] and Keyvani et al. (2014) [22].

To better understand the effect of PAM, a clear and unambiguous SEM (scanning electron microscope) image was presented in Fig. 3(d). The surface morphology of floc was changed significantly after being flocculated by PAM. A round and layered structure with a large number of pores was found on the surface of floc. The particles were gathered and compacted by PAM. The porous feature is expected to exert positive effects on bridging adsorption and enmeshment [14].
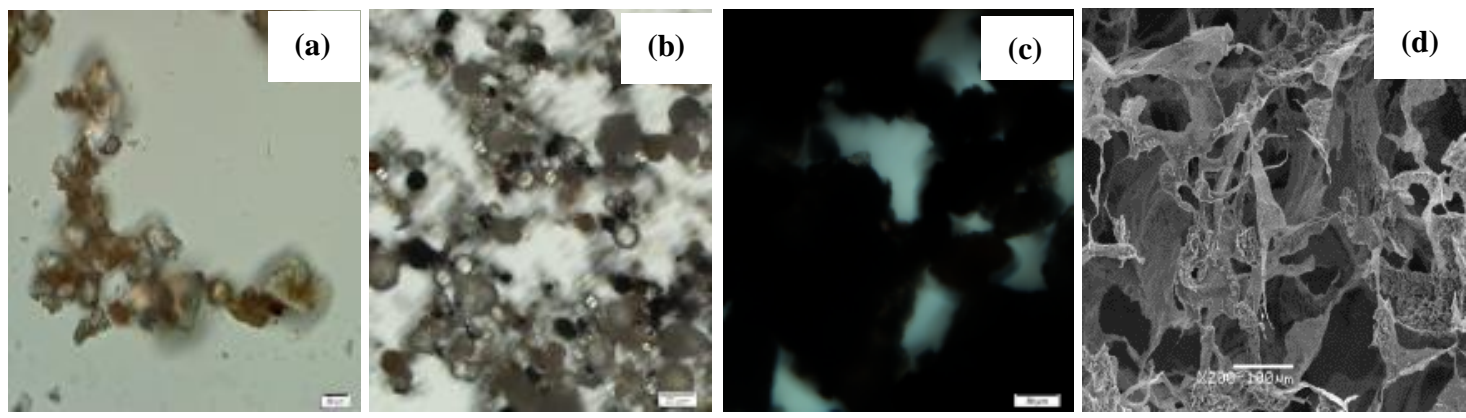

Fig. 3. Selected images of four flocs types: (a) sand, (b) fly ash, (c) coal, obtained by optical microscopy and (d) obtained by scanning electron microscope

\subsection{Fractal Dimension Analysis}

Many studies have been noticed and used fractal dimension for defining floc structure $[25,26]$. In this study, a normal distribution of the fractal dimensions for a given floc size has been observed (Fig. 4). The calculated fractal dimension of the sand-PAM samples ranged from 1.044 to 1.415 with an average of 1.15 and a standard deviation of 0.069 for 649 individual flocs. This result is in a good agreement with the Lech's results. The fractal dimension of $\mathrm{Al}$ sludges ranged from 1.3713 to 1.4858 , and the values of $\mathrm{Fe}$ sludges ranged from 1.2478 to 1.3564 [27]. Additionally, the fractal dimension of APAM is 1.35 [14]. This implies that the applied method adequately fits the set of images of flocs.

The range of variations in objects selected from the surface of the images is sufficient to find out the self-similarity of the analyzed flocs. The fractal dimension of flocs identified on the surface of images of sand-PAM samples is indicative of their fractal nature and structure. The jagged and porous structure of flocs is thus mathematically validated. The PAM flocs characterized by a lower value of fractal dimension 
have a greater ability to adsorb suspensions during sweep flocculation than the aggregates with a higher value of fractal dimension.

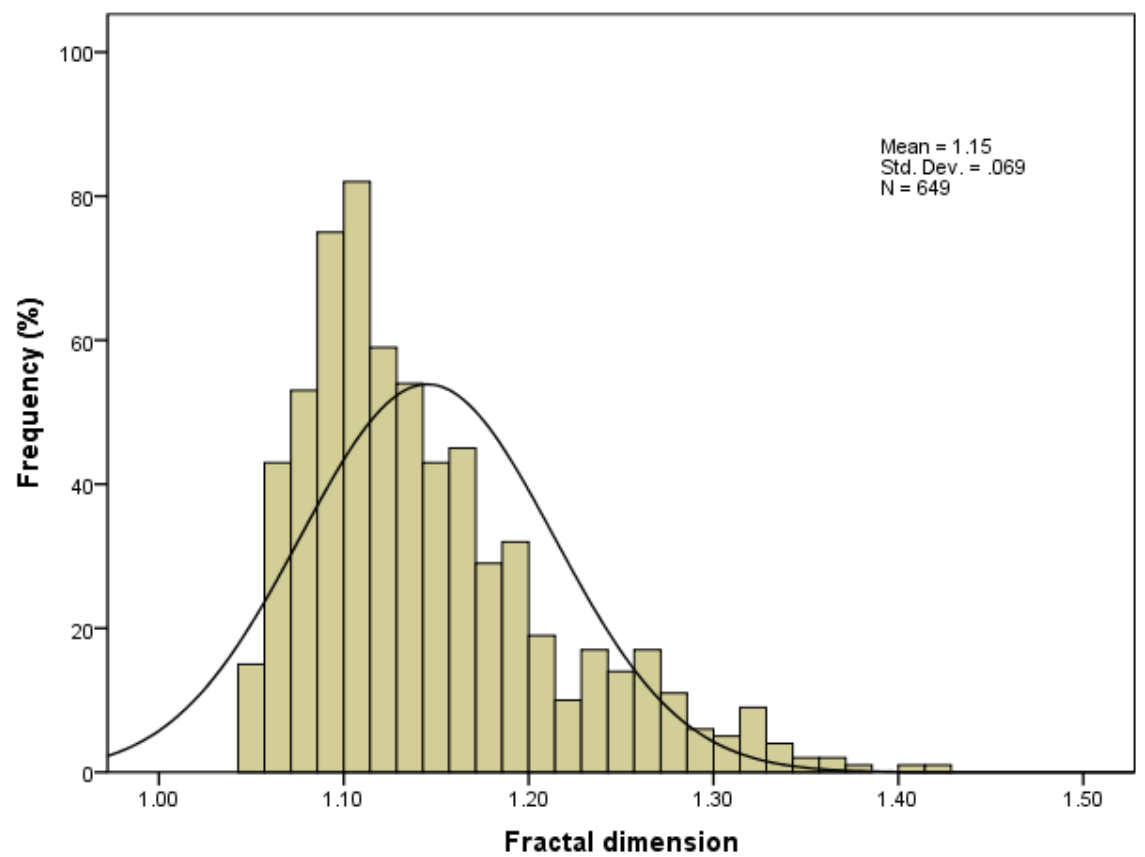

Fig. 4. Distribution charts for Flocs

\subsection{Effect of the Flocculant Dose on the Settling Velocity}

The broader goal of examining the floc properties was ultimately to better understand the settling velocity relationship with flocculant dose under different conditions. Figure 5 shows a plot of settling velocity as a function of flocculant dose for different suspension kinds and concentrations. As show in Fig. 5, the settling velocity increased with increasing flocculant dosage. A less dosage resulted in non-uniform distribution of flocculant in the suspension environment, which limited the combination between suspended particles and PAM. However, for a high dosage, the result indicated a substantial reduction in PAM removal efficiency. The reason is that when the flocculant dosage exceeds a certain value, further increases in flocculant dosage will cause PAM molecules to wrap around flocs such that the flocculant exhibits protection rather than flocculation. Therefore, an appropriate flocculant dosage is required in flocculation process.
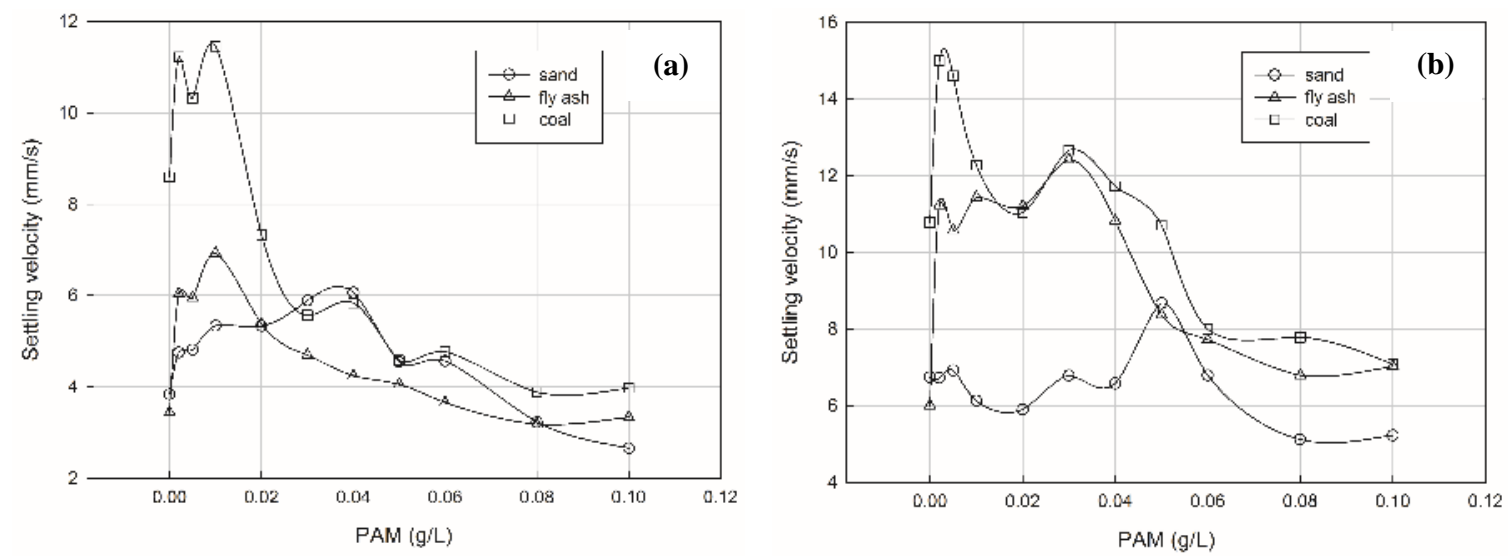

Fig. 5. Observed settling velocity versus flocculant doses between 0 and $0.1[\mathrm{~g} / \mathrm{L}]$, with suspension concentrations are $5[\mathrm{~g} / \mathrm{L}]$ (a) and $15[\mathrm{~g} / \mathrm{L}](\mathrm{b})$.

Suspension of different concentrations generally exists in real water samples. For further clarification about the point above, comparison between the three suspensions was made from another perspective. As 
such, the flocculation efficiency of PAM may vary depending on the sample to which it is applied. The effect of suspension concentration on settling velocity was investigated at the flocculant dosage of $0.04 \mathrm{~g} / \mathrm{L}$. The results are shown in Fig. 6. As shown in Fig. 6, it was found that the settling velocity of flocs sharply increased with the increase in suspension concentration below $10 \mathrm{~g} / \mathrm{L}$. However, when suspension concentration was further increased from $10 \mathrm{~g} / \mathrm{L}$ to $30 \mathrm{~g} / \mathrm{L}$, settling velocity remained basically stable with less variation, which could be attributed to the limited flocculant dosage. A higher dosage of the flocculant is required to remove increasing concentration of particles from water. The reason is that with the increase in suspension concentration the distribution of flocculant macromolecules within the volume of suspension slows down.

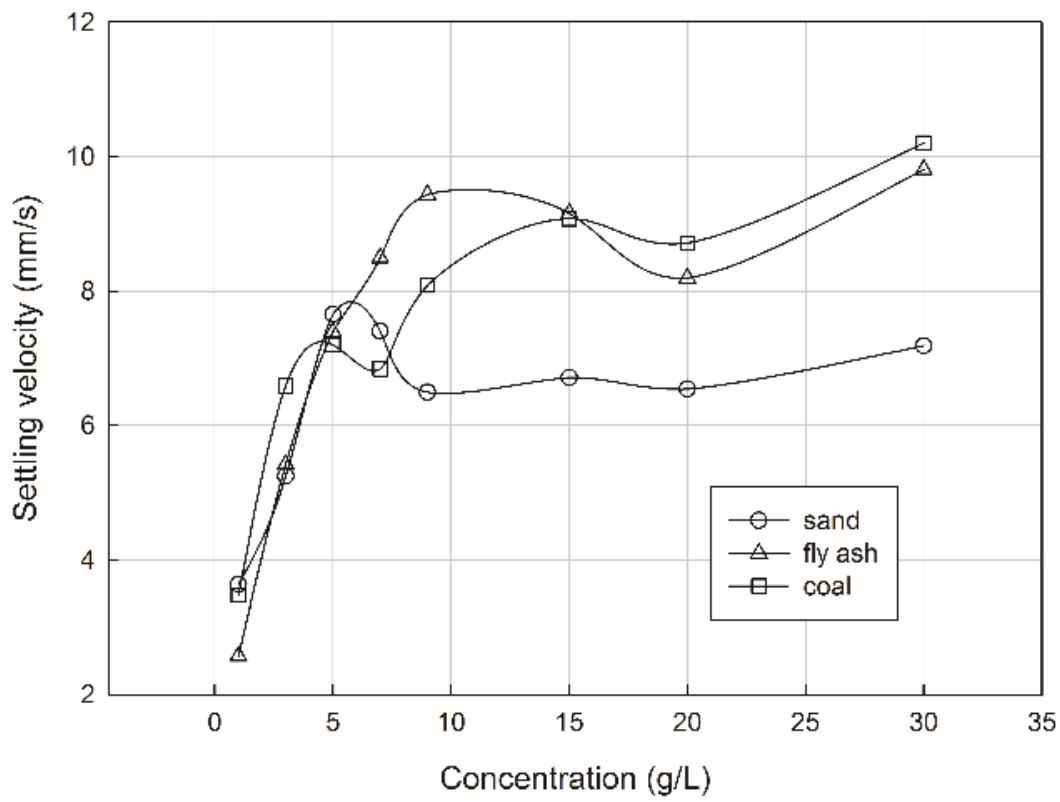

Fig. 6. Observed settling velocity versus suspension concentrations between 1 and 30 [g/L], with flocculant dose is $0.04[\mathrm{~g} / \mathrm{L}]$.

\subsection{Analyzing Possible Flocculation Mechanism}

PAM has been used in flocculation processes for water purification and is known to lower flocculation dosage requirements and increase settlement. The possible flocculation mechanism of PAM was analyzed besides investigation of the settling velocity. It may be that PAM is able to adsorb in a patchwise manner and bind particles by electrostatic attraction or by a bridging mechanism. The flocculation mechanism of PAM could be summarized as follows. In acidic environments charge neutralization had a key role in the flocculation process. Additionally, in alkaline and neutral conditions, adsorption and bridging effect dominated the process. Finally, flocs settled down to the bottom through the bridging effect, thus resulting in enmeshment and sweeping effects that seized particles from water $[28,29]$.

\section{Discussion}

In this study the effect of PAM on settling velocities of different suspensions were evaluated. Results revealed the average fractal dimension of sand-PAM flocs samples was 1.15. Other researchers who measured and calculated the fractal dimension of APAM is 1.35 [14]. In addition, settling velocities were measured at different suspension types and concentrations. Results revealed a faster settling velocity for the same suspension when the PAM dosage was appropriate. However with increasing PAM dosage, results revealed as expected in a decrease in settling velocities. Compared with the previous studies [30], the results are credible. Figure 3 gave a reasonable interpretation between the above results and theory. PAM has a significant effect on suspension settling rate. This is due to the fact that an appropriate PAM dosage leads to better bridging adsorption and enmeshment [14]. 


\section{Conclusions}

This laboratory study has examined the floc characteristics of PAM under variable flocculant dosage, suspension kind and suspended particles concentration. The main findings can be summarized as:

(1) The applied image analysis method revealed that the examined flocs were composed of self-similar aggregate-flocs with fractal properties. SEM images and the value of surface fractal dimension quantitatively describe the aggregate-flocs. The aggregate-flocs were characterized by lower values of surface fractal dimension and a round and layered structure with a large number of pores, which were observed in SEM analyses.

(2) Flocculation of PAM was evaluated by settlement test procedure using the sand, fly ash and coal suspension. The settling velocity in each experimental condition was measured in a settling column. Flocculant dosage and suspension concentration determine the settling velocity and by this affect the flocs characteristics of the PAM. An appropriate PAM dosage is an excellent candidate as efficient flocculant for the treatment of wastewater.

(3) The knowledge of aggregation mechanisms of flocs was the key parameter required. Charge neutralization, sweeping by precipitation enmeshment and bridging had important roles in the flocculation process. Moreover, these mechanisms may explain the influence of PAM on flocs characteristics.

\section{Nomenclature}

$v_{s t}: \quad$ is the settling velocity of an individual floc

$\theta: \quad$ is a particle shape factor

$g: \quad$ is the gravitation acceleration

$\mu: \quad$ is the water dynamic viscosity

$\rho_{p}: \quad$ is the density of primary particles

$\rho_{w}: \quad$ is the water density

$d_{50}: \quad$ is the median size

$d: \quad$ is the floc size

$D_{f}: \quad$ is the fractal dimension

$\phi: \quad$ is the effect of the size distribution of the primary particles

Re: $\quad$ is the particle Reynolds number

$N: \quad$ is the number of primary particles in the floc of linear size $d$

$d: \quad$ is the size of the aggregate floc

$d_{p}: \quad$ is the size of the primary particles

$v: \quad$ is the kinematic viscosity

$\Delta Z: \quad$ is the vertical displacement of the floc centroid

$\Delta t: \quad$ is the time over which the floc was tracked

$N_{r}: \quad$ is a number covering its image

$r: \quad$ is the size

\section{Acknowledgments}

The authors wish to thank the National Natural Science Foundation of China (Grant No. 51279170), the Science and Technology Project of Ministry of Housing and Urban-Rural Development of China (Grant No. 2015-K7-009) and Qing Lan Project (2016). This paper benefited from valuable and critical suggestions from the referees and the editor. 


\section{References}

[1] K. A. Gray, C. H. Yao, and C. R. O’Melia, "Inorganic metal polymers-preparation and characterization," American Water Works Association, vol. 87, pp. 136-146, 1995.

[2] F. Xiao, J. Ma, P. Yi, and J. C. H. Huang, "Effects of low temperature on coagulation of kaolinite suspensions," Water Research, vol. 42, pp. 2983-2992, 2008.

[3] S. Hussain, J. van Leeuwen, C. Chow, S. Beecham, M. Kamruzzaman, D. S. Wang, M. Drikas, and R. Aryal, "Removal of organic contaminants from river and reservoir waters by three different aluminum-based metal salts: Coagulation, adsorption and kinetics studies," Chemical Engineering Journal, vol. 225, pp. 394-405, 2013.

[4] H. Song, S. F. Zhang, X. C. Ma, D. Z. Wang, and J. Z. Yang, "Synthesis and application of starchgraft-poly (AM-co-AMPS) by using a complex initiation system of CS-APS, Carbohyd," Polym, vol. 69, pp. 189-195, 2007.

[5] Y. M. Wu and N. N. Zhang, "Aqueous photo-polymerization of cationic polyacrylamide with hybrid photo-initiators," Journal of Polymer Research, vol. 16, pp. 647-653, 2009.

[6] Z. Yang, B. Yuan, X. Huang, J. Zhou, J. Gai, H. Yang, A. Li, and R. Cheng, "Evaluation of the flocculation performance of carboxymethyl chitosan-graft-polyacrylamide, a novel amphoteric chemically bonded composite flocculant," Water Research, vol. 46, no. 1, pp. 107-114, 2012.

[7] J. C. Winterwerp, "A simple model for turbulence induced flocculation of cohesive sediment," Journal of Hydraulic Research, vol. 36, no. 3, pp. 309-326, 1998.

[8] C. Kranenburg, "The fractal structure of cohesive sediment aggregates," Estuarine, Coastal and Shelf Science, vol. 39, no. 5, pp. 451-460, 1994.

[9] X. Y. Li and B. E. Logan, "Permeability of fractal aggregates," Water Research, vol. 35, pp. 3373-3380, 2001.

[10] R. L. Soulsby, Dynamics of Marine Sands. London, UK: Thomas Telford Publications, 1997.

[11] R. J. Gibbs and L. N. Konwar, "Effect of pipetting on mineral flocs," Environmental Science and Technology, vol. 16, no. 2, pp. 119-121, 1982.

[12] W. Yu, J. Gregory, L. C. Campos, and N. Graham, "Dependence of floc properties on coagulant type, dosing mode and nature of particles," Water Research, vol. 68, pp. 119-126, 2015.

[13] F. D. Renzo and P. Enrico, "Wall effects on the sedimentation velocity of suspensions in viscous flow," AICHE Journal, vol. 42, pp. 927-931, 1996.

[14] H. Zheng, J. Ma, C. Zhu, Z. Zhang, L. Liu, Y. Sun, and X. Tang, "Synthesis of anion polyacrylamide under UV initiation and its application in removing dioctyl phthalate from water through flocculation process," Separation and Purification Technology, vol. 123, pp. 35-44, 2014.

[15] F. Concha, N. N. Rulyov, and J. S. Laskowski, "Settling velocities of particulate systems 18: Solid flux density determination by ultra-flocculation," International Journal of Mineral Processing, vol. 104-105, pp. 53-57, 2012.

[16] R. G. Kumar, K. B. Strom, and A. Keyvani, "Floc properties and settling velocity of San Jacinto estuary mud under variable shear and salinity conditions," Continental Shelf Research, vol. 30, pp. 20672081, 2010.

[17] S. J. Smith and C. T. Friedrichs, "Size and settling velocities of cohesive flocs and suspended sediment aggregates in a trailing suction hopper dredge plume," Continental Shelf Research, vol. 31, pp. S50-S63, 2011.

[18] A. Terfous, A. Hazzab, and A. Ghenaim, "Predicting the drag coefficient and settling velocity of spherical particles," Powder Technology, vol. 239, pp. 12-20, 2013.

[19] L. Smoczyński, "Aggregation of the silica suspension by AL-coagulants," Polish Journal of Chemistry, Vol. 74, pp.1617-1624, 2000.

[20] Y.-C. Hsieh, W.-S. Shyu, and Y.-L. Yeh, "Relationship between fractal dimension and hydraulic conductivity of monodisperse soil structure," Taiwan Water Conservancy, vol. 62, no. 3, pp. 66-74, 2014.

[21] A. Vahedi and B. Gorczyca, "Predicting the settling velocity of flocs formed in water treatment using multiple fractal dimensions," Water Research, vol. 46, pp. 4188-4194, 2012.

[22] A. Keyvani and Kyle Strom, "Influence of cycles of high and low turbulent shear on the growth rate and equilibrium size of mud flocs," Marine Geology, vol. 354, pp. 1-14,2014.

[23] H. Liu, X. Yang, Y. Zhang, Hangcheng Zhu, Juming Yao, "Flocculation characteristics of polyacrylamide grafted cellulose from phyllostachys heterocycla: An efficient and eco-friendly 
flocculant," Water Research, vol. 59, pp. 165-171, 2014.

[24] K. J. Nyembwe, M. E. Makhatha, and T. Madzivhandila, "Physico-chemical characterization of South African waste moulding sands," Engineering Journal, vol. 20, no. 5, pp. 35-48, 2016.

[25] A. Khelifa and P. S. Hill, "Models for effective density and velocity of flocs," Hydraulic Research, vol. 44, no. 3, pp. 390-401, 2006.

[26] M. Son and T. J. Hsu, "Flocculation model of cohesive sediment using variable fractal dimension," Environmental Fluid Mechanics, vol. 8, no. 1, pp. 55-71, 2008.

[27] L. Smoczyński, H. Ratnaweera, M. Kosobucka, and M. Smoczyński, "Image analysis of sludge aggregates," Separation and Purification Technology, vol. 122, pp. 412-420, 2014.

[28] X. J. Yang and L. Ni, "Synthesis of hybrid hydrogel of poly (AM co DADMAC)/silica sol and removal of methyl orange from aqueous solution," Chemical Engineering Journal, vol. 209, pp. 194-200, 2012.

[29] D. Vandamme, K. Muylaert, I. Fraeye, and I. Foubert, "Floc characteristics of Chlorella vulgaris: Influence of flocculation mode and presence of organic matter," Bioresource Technology, vol. 151, pp. 383-387, 2014.

[30] M. K. H. Winkler, J. P. Bassin, R Kleerebezem, R. G. J. M. van der Lans, and M. C. M. van Loosdrecht, "Temperature and salt effects on settling velocity in granular sludge technology," Water Research, vol. 46, pp. 3897-3902, 2012. 